\title{
Novel Process for Removal and Recovery of Vapor-Phase Mercury
}

\author{
Technical Progress Report \\ Covering $3^{\text {rd }}$ Quarter FY1999 \\ Contract Number DE-AC22-95PC95257 \\ ADA Project Number 4416

\begin{abstract}
prepared for
AAD Document Control

Pittsburgh Energy Technology Center

P. O. 10940, MS 921-143

Pittsburgh, PA 15236-0940

Mr. Tony Mayne

Contracting Officer's Representative

MS 922-260

412-892-4673

prepared by

ADA Technologies, Inc.

304 Inverness Way South, Suite 365

Englewood, CO 80112
\end{abstract}

July 23, 1999 


\section{Novel Process for Removal and Recovery of Vapor-Phase Mercury}

The purpose of this project is to investigate the application of a sorbent-based process for removing and recovering mercury in the flue gas of coal-fired power plants. The process is based on the sorption of mercury by noble metals and the regeneration of the sorbent by thermal means, recovering the desorbed mercury for recycling. ADA Technologies holds a patent on this process (US 5,409,522) and has tested it under conditions typical of municipal waste incinerators. In this process, the noble metal sorbent is thermally regenerated, and the mercury is recovered for commercial recycle or disposal. ADA has adopted the name "Mercu-RE" to describe its process.

ADA has been testing its process under conditions typical of coal-fired power plants where the mercury concentration is low (below $10 \mu \mathrm{g} / \mathrm{m}^{3}$ ) and little pressure drop can be tolerated. The objective of this program is to develop the Mercu-RE process as a suitable mercury emission control technology for use at coal-fired power plants.

\section{Overview of Progress}

Phase I tasks 1 through 5 were completed as of October 1997. No additional activities have occurred under those tasks. Current period activities are summarized by task:

\section{II-6 Modify 20-acfm Skid}

ADA completed the design modifications to ADA's mercury analyzer. These changes were designed to improve signal to noise ratio, eliminate thermal drift, and simplify operation. An initial trace from the remodeled system is shown in Figure 1. The trace shows repeated sampling of a $10 \mu \mathrm{g} / \mathrm{m}^{3}$ elemental mercury stream. The analyzer response is consistent over the test span of several hours and displays very little drift. The absolute noise level is on the order of $0.2 \mu \mathrm{g} / \mathrm{m}^{3}$. Additional testing is underway to determine the analyzer performance in simulated and real flue gas. Following the successful completion of the evaluation testing, the revised unit will be tested on the skid at Hudson. Successful operation of the analyzer will enhance our data tracking ability during the field test. 


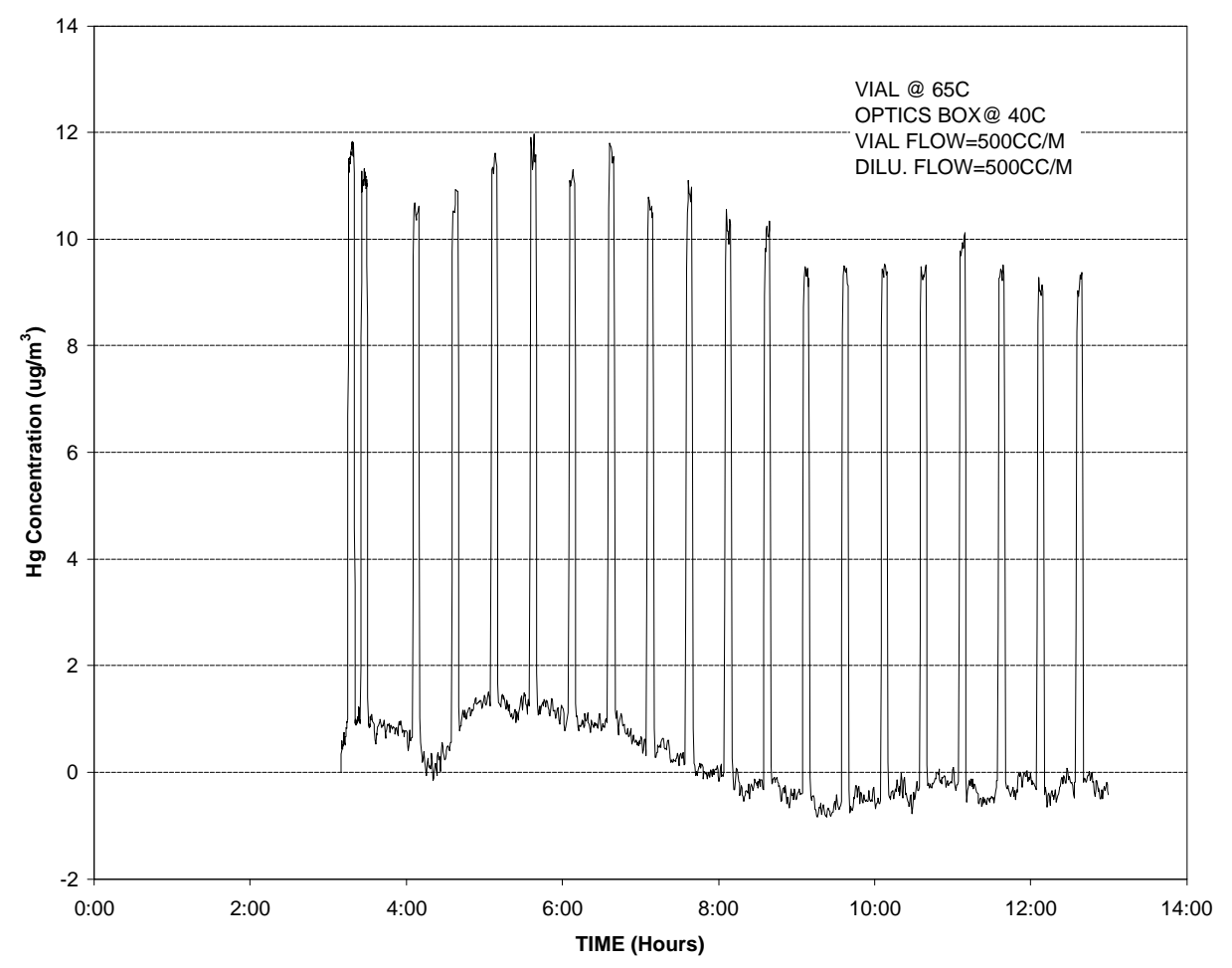

Figure 1. Test trace from remodeled mercury analyzer.

\section{II-7 Establish Routine Operation at Pilot Combustor}

The last samples obtained during the testing at CONSOL yielded conflicting data regarding the effectiveness of the sorbent. Iodated-carbon traps (IC traps) indicated 65\% removal across each of the two sorbent vessels, whereas simultaneous Ontario-Hydro sampling indicated no removal. Laboratory data from last quarter showed loss of noble metal from the sorbent and a decrease in sorbent effectiveness. In the current quarter we continued examination of the fresh and spent sorbent to ascertain if the crystallite size of the noble metal had changed. Results from x-ray diffraction studies and scanning electron microscopy (SEM) proved inconclusive - presumable due to the small size of the crystallites and relatively low initial loading of metal. The SEM photos showed little difference between the fresh and spent sorbent, although there was some indication of spalling. Spalling would be consistent with condensation within the sorbent pores, as it can result from the explosive evaporation of moisture from within the material. 


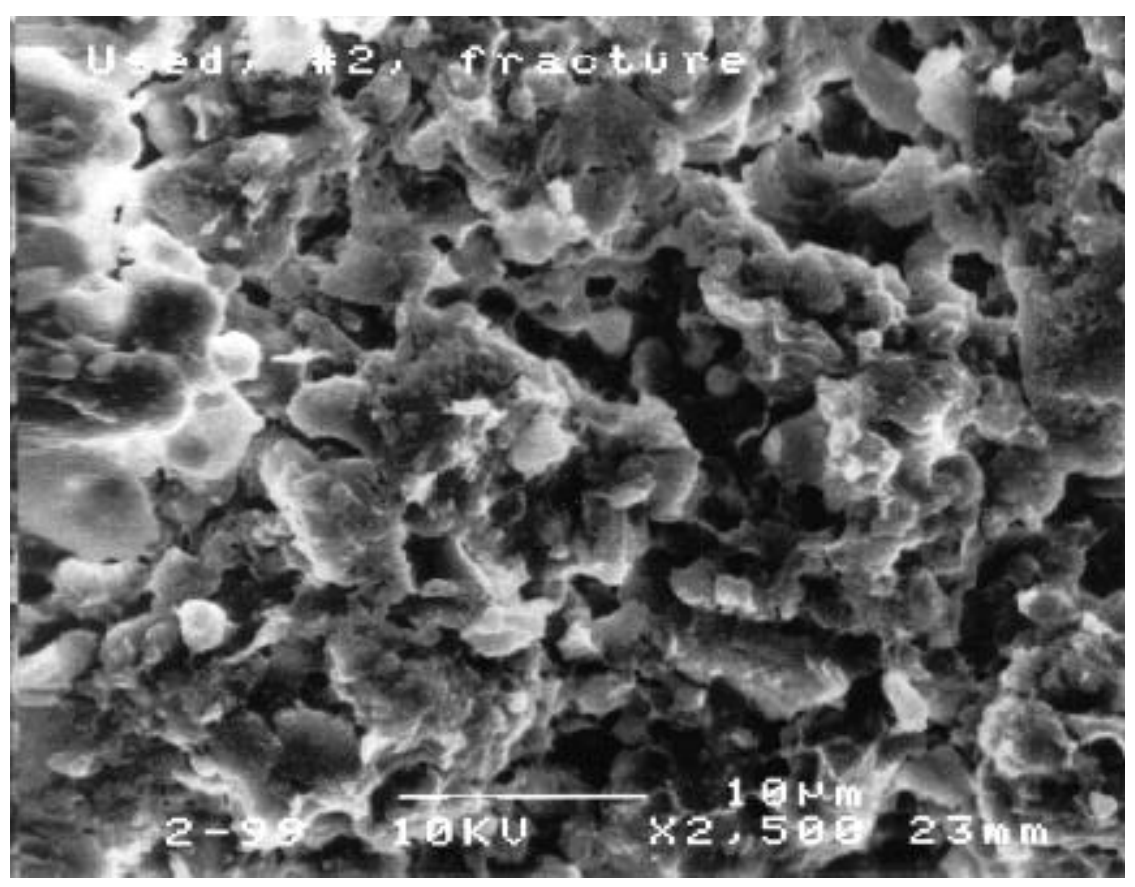

Figure 2. SEM photograph of spent sorbent. Image is of an internal surface.

\section{II-8 Install and Shakedown Pilot System at Utility Site}

At the end of March the equipment skid was relocated to Hudson Station in Jersey City, NJ. The unit is located within a $30-\mathrm{ft}$ by $8-\mathrm{ft}$ office trailer that serves as equipment enclosure and office. During April, ADA completed modifications to the trailer and test equipment, including the installation of an isolation valve, computer interface with the onsite blower that provides flue gas to the skid, and improved airflow within the trailer. A key change in the test equipment was the installation of new sorbent monoliths. The new sorbent is ADA's BVI formulation deployed onto a ceramic monolith. This contrasts with the metal monoliths and ceramic rings used during the testing at CONSOL. The ceramic monoliths are 7.5-inch diameter by 7-inch long, 200-cpsi cordierite, manufactured by Corning. Operation of the skid was modified to use only one vessel, R101, for the sorption testing at Hudson. Because regeneration time is less than sorption time, the use of one vessel will allow an individual sorbent sample to achieve more time on flue gas.

In early May the power plant went down for scheduled maintenance. During that outage, ADA fixed an electrical interference problem that was hampering operations of the skid. Skid operation began shortly thereafter.

\section{II-9 Test Long-Term Performance at Utility Site}

Routine operation of the test equipment at Hudson Station began in mid-May. During the first week of operation, ADA contracted with CONSOL to pull Ontario-Hydro samples of the inlet and outlet gas at the skid. ADA staff, with the assistance of Maplewood Testing, pulled IC traps at that time. Triplicate inlet/outlet samples were taken on May $19^{\text {th }}$. The 
flue gas which feeds the skid was withdrawn downstream of the Hudson ESP. In addition, the sample port was also downstream of a small baghouse located on the ADA skid. This baghouse is designed to minimize the effects of ash for the initial test period at the power plant. Thus, there was virtually no ash present in the samples. The sample results are depicted in Figure 3. The Ontario-Hydro $(\mathrm{OH})$ samples provide speciation information regarding whether the captured mercury is elemental or oxidized. The IC traps record only total mercury. The results mimic those seen during the December runs at CONSOL - the $\mathrm{OH}$ samples indicate no removal, while the IC traps show $83 \pm 5 \%$ removal across the sorbent. Analysis of the coal to cross-check the inlet mercury values is still pending.

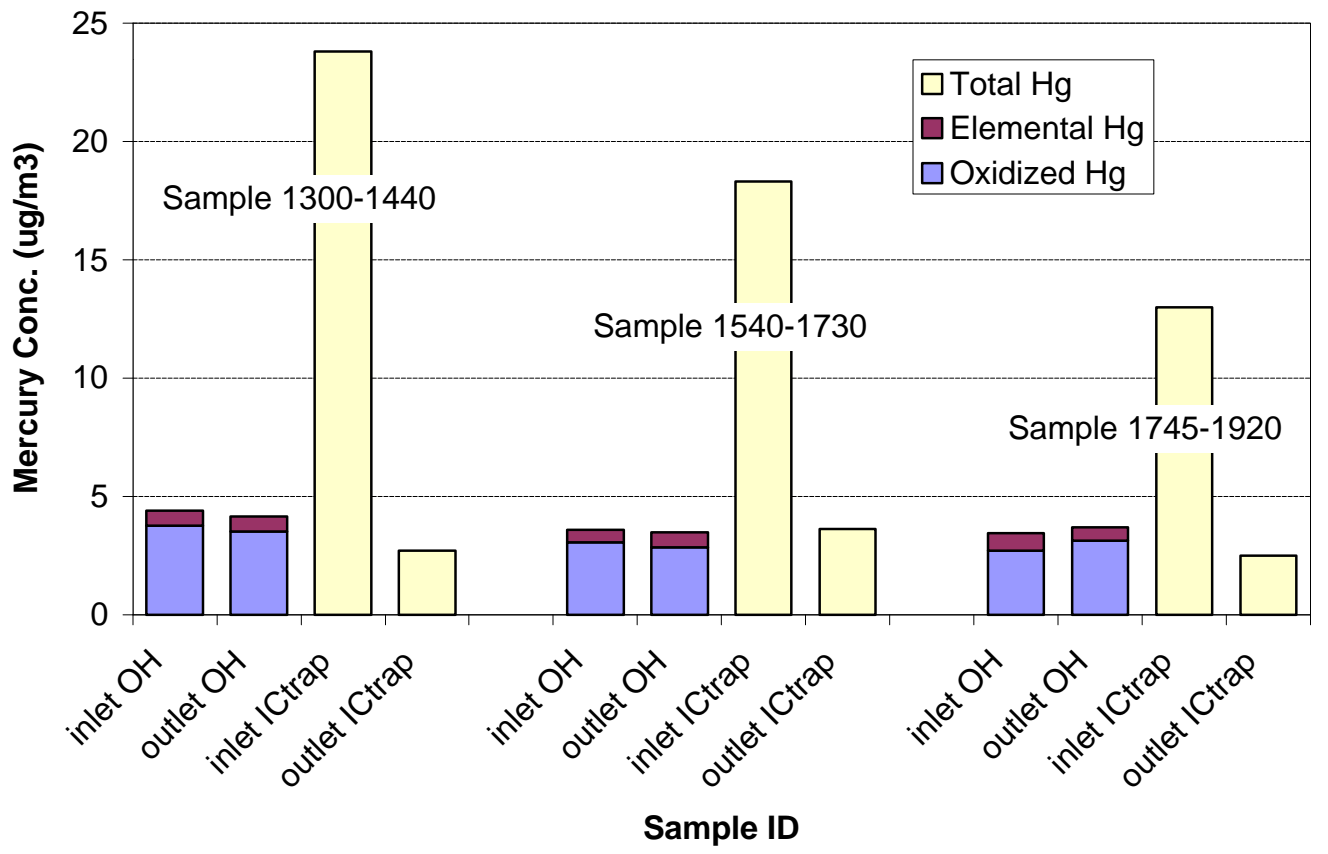

Figure 3. Comparison of Ontario-Hydro (OH) and Iodated-carbon (IC) trap data from 05/19/99 testing at Hudson Station.

The $\mathrm{OH}$ samples indicated that $84 \%$ of the vapor-phase mercury in the Hudson flue gas was oxidized. This is typical of an eastern bituminous coal and consistent with previous data from the plant. Similar speciation was found during the December sampling at CONSOL, where another eastern coal (Rend Lake) was being used. Previous mercury levels recorded at Hudson were around $4 \mu \mathrm{g} / \mathrm{m}^{3}$, consistent with the $\mathrm{OH}$ results listed above. Mercury levels of 15 to $20 \mu \mathrm{g} / \mathrm{m}^{3}$, like those indicated by the IC trap data, are unlikely. Once the coal-mercury data are available we will be able to assess if those values are realistic.

On the basis of the $\mathrm{OH}$ results, the sorbent monoliths are removing none of the incoming mercury. These monoliths were installed fresh for the Hudson tests and thus had very 
little (less than 20 hours) time on flue gas at the time of these tests. Small versions of the monoliths were tested in ADA's laboratory prior to installation in the 20-cfm skid and those tests (with elemental mercury) indicated high removal efficiencies. Although we have also demonstrated the ability to remove mercuric chloride in the laboratory, it is possible that the sorbent has a significantly lower capacity for oxidized mercury than for elemental. Further laboratory tests are being carried out to test the capacity of the sorbent for mercuric chloride in air and in simulated flue gas. Discussions are also ongoing with Frontier Geosciences (Seattle, WA) to determine if some interference with the IC traps may cause abnormally high readings.

\section{II-10 Prepare Economic Assessment for Full-Scale System}

No work on this task.

\section{II-11 Prepare Documents}

Monthly reports for March through May (status, summary, cost management, and milestone schedule) were submitted during the quarter. In June, ADA presented the paper "Removal of Mercury from Coal-Combustion Flue Gas Using Regenerable Sorbents" at the Air and Waste Management Association Meeting in St. Louis.

ADA requested and received a no-cost extension of the project through August, 2000. The extension was requested to allow the field testing at Hudson Station to run for the initially planned nine to twelve months.

\section{Project Plan for Next Quarter}

The major activity of the next quarter is support of the equipment operation at Hudson Station. ADA has contracted with PSE\&G's testing division (Maplewood Testing Services, Maplewood, NJ) to pull samples and carry out routine maintenance while the equipment is at the New Jersey site. ADA staff will also make periodic visits to the site.

The modified mercury analyzer will undergo testing in ADA's laboratory to confirm its ability to track mercury in simulated flue gas. Following those tests, the unit will be taken to a utility site for field evaluation. If successful, the analyzer will replace the costly and slow field sampling required to track sorbent performance.

Further testing is underway at ADA to elicit the capacity of this sorbent formulation for oxidized mercury. These tests involve a 1-inch diameter monolith and ADA's sorbent test system. If necessary, ADA will make changes to the field unit to boost the capacity of the sorbent. Changes may include additional noble metal sorbent or modification of the formulation to enhance capture of oxidized mercury. ADA will also be running further tests to check the efficiency of the sorbent regeneration process. 